\title{
1 The conundrum of the treatment for left main coronary disease
}

2

Mario Gaudino MD르 Nick Freemantle PhD², Michael E. Farkouh MD, MSc ${ }^{3}$

${ }^{1}$ Department of Cardiothoracic Surgery, Weill Cornell Medicine, New York, New York

${ }^{2}$ Institute of Clinical Trials and Methodology, University College London, London, UK

${ }_{3}^{3}$ Peter Munk Cardiac Centre and the Heart and Stroke Richard Lewar Centre, University of Toronto, Toronto, Ontario, Canada

Word count: 1297

Funding: None

Disclosures: MG none, NF has received funding for research, consulting and travel from AZ, Allergan, Ipsen, Sanofi Aventis, Novo Nordisk, Akcea, Takeda, PTC, institutional support for education and methodological advice from EACTS; MEF receives research grant support from Amgen, Novo-Nordisk and Novartis

\section{Address for correspondence}

Mario Gaudino, MD

Department of Cardiothoracic Surgery, Weill Cornell Medicine

525 E 68th St, New York, NY 10065

Telephone: +1 2127469440 Fax: +1 2127468080

E-mail:mfg9004@med.cornell.edu 
1 New data published in the last two years have made the process of making evidence-based

2 therapeutic decisions regarding the optimal revascularization strategy in patients with left main

3 coronary disease (LMD) increasingly challenging.

4 Often, the cardiovascular community turns to meta-analyses to address controversial topics. In

5 an individual data pooled analysis of 11 randomized trials and more than 11,000 patients

6 published in 2018, Head and colleagues found that in patients with multivessel disease or left

7 main stenosis, the use of percutaneous coronary intervention ( $\mathrm{PCl}$ ) was associated with a

8 significant increase in mortality at 5 years follow-up when compared to coronary artery bypass

9 grafting (CABG) (hazard ratio [HR] 1.20, 95\% confidence interval [CI] 1.06-1.37, $\mathrm{p}=0.004) .^{1}$

10 Mortality was similar between the interventions in patients with left main disease $(10.7 \%$ after

$11 \mathrm{PCl}$ vs $10.5 \%$ after CABG, HR 1.07, 95\% $\mathrm{Cl} 0.87-1.33, \mathrm{p}=0.52)$, regardless of diabetes status and

12 Synergy Between Percutaneous Coronary Intervention With TAXUS and Cardiac Surgery

13 (SYNTAX) score. The presence of LMD was not a significant effect modifier, providing no

14 statistical support for the concept that the relationship between $\mathrm{PCl}$ and CABG is systematically

15 different in the presence of LMD. ${ }^{2}$

16 The Evaluation of XIENCE versus Coronary Artery Bypass Surgery for Effectiveness of Left Main

17 Revascularization (EXCEL) trial randomized 1905 patients with LMD to CABG or PCI and

18 published its 5-year results in $2019 .^{3}$ In EXCEL, there was no statistically significant difference in

19 the primary composite outcome of death, myocardial infarction (MI) and stroke between the

20 two treatment arms. The Society for Cardiovascular Angiography and Intervention (SCAI)

21 definition of $\mathrm{MI}$, that intrinsically favors $\mathrm{PCl}$ (due to the higher enzymatic release associated 
1 with surgical manipulation after $(A B G)$, was approved by the Steering Committee and used as

2 the main MI definition in the trial. The protocol pre-specified however that the MI rates would

3 also be calculated using the more widely adopted Universal Definition of Myocardial Infarction.

4 In EXCEL, the rate of perioperative MI by the SCAI definition in the surgical arm was higher than

5 in all the other major CABG vs $\mathrm{PCl}$ trials $\mathrm{s}^{4,5}$ and was mainly responsible for the neutral result of

6 the trial (as the incidence of all non-perioperative events was higher in the $\mathrm{PCl}$ arm). To date,

7 the MI results based on the Universal Definition have not been published in peer-reviewed

8 journals, and the EXCEL trial has attracted considerable controversy. ${ }^{6,7}$ An analysis of mortality

9 at 5 years (arguably the most important outcome) found an excess risk in the $\mathrm{PCl}$ group (odds

10 ratio $1.38,95 \% \mathrm{Cl} 1.03-1.85)$.

11 A month later, the Nordic-Baltic-British Left Main Revascularisation (NOBLE) trial published its

12 5-year results. ${ }^{8}$ NOBLE enrolled 1,201 patients with LMD who were randomized to CABG or PCI

13 and its primary outcome was a composite of death, non-periprocedural MI, stroke and repeat

14 revascularization. At 5 years, the primary outcome occurred significantly more frequently in the

$15 \mathrm{PCl}$ arm (HR 1.58, 95\% $\mathrm{Cl} 1.24-2.01, \mathrm{p}=0.0002)$. No significant excess of death in the

16 percutaneous arm was noted ( $\mathrm{HR} 1.08,95 \% \mathrm{Cl} 0.74$ to $1.59, \mathrm{p}=0.70)$, although the number of

17 deaths was small and the resulting confidence intervals were wide.

18 The publication of the two trials with apparently divergent results was accompanied by a fiery

19 debate in the cardiovascular community, in particular with regard to the excess of deaths seen

20 in EXCEL and not significantly so in NOBLE, and on the different definitions of MI used in the

21 trials $s^{6,7}$. 
1 In this issue of the European Heart Journal, Ahmad et al present a trial-level meta-analysis of

2 the five trials that compared $\mathrm{CABG}$ and $\mathrm{PCl}$ in patients with $\mathrm{LMD} \cdot{ }^{9}$ At a mean weighted follow-

3 up of 67 months, the authors found no difference in mortality, a higher rate of repeat

4 revascularization and non-periprocedural $\mathrm{MI}$ in the $\mathrm{PCl}$ arm, and a higher rate of periprocedural

$5 \mathrm{Ml}$ in the surgical arm. This meta-analysis is an important contribution as it evaluates the

6 totality of the randomized evidence addressing the question. There are, however, important

7 limitations of pooling trials from very different eras and with major procedural and

8 methodological differences (the increase in statistical precision come at the price of a decrease

9 in clinical relevance).

10 So, what is the take home message from the Ahmad meta-analysis and the formidable analytic

11 effort devoted to the definition of the recommended treatment for patients with LMD in recent

12 years? Shall the clinician dealing with the decision to indicate CABG or PCl in a patient with $L M D$

13 during the daily Heart Team discussion be concerned by the excess death seen in EXCEL or be

14 reassured by the lack of significant difference in NOBLE and in Ahmad trial level meta-analysis?

15 Is CABG associated with a higher or lower risk of $\mathrm{MI}$ and is perioperative $\mathrm{MI}$ different from

16 spontaneous MI?

17 Even if confused by the apparently discordant results and unfamiliar with the subtle

18 methodological differences probably responsible for them, every clinician is well aware of the

19 different mechanisms of these two revascularization strategies, ${ }^{10}$ and is equipped to weigh the

20 risk:benefit equation for an individual patient. Currently, for patients with multivessel disease

21 who are suitable for both $\mathrm{CABG}$ or $\mathrm{PCl}$, the evidence is convincing that $\mathrm{CABG}$ is associated with 
1 a lower risk of death and cardiac events in the longer term; based on the available data it does

2 not seem that things are different for patients with left main stenosis. However, in patients for

3 whom surgery presents an unreasonable risk or who are more interested in short-term

4 outcomes, $\mathrm{PCl}$ is a very welcome alternative (Figure $\mathbf{1}$ ).

5 Thinking of the 50-year old single parent caring for their three children, the 75-year old retired

6 veteran with lung cancer impatient to walk his daughter down the aisle next month, the

7 professional airline pilot, or the busy businessman in the middle of a multimillion-dollar

8 transition that really cannot wait, we all recognize the challenges of translating this evidence

9 into clinical practice. The discrepant results of the trials may very well be the results of the fact

10 that we are dealing with a heterogeneous group of patients- a few with isolated LMD versus

11 those with LMD and multivessel disease, although there is currently no good evidence to

12 support the concept of LMS as a discrete patient group with a different treatment effect. It is

13 highly likely that one size does not fit all in clinical practice! CABG and PCI should not be seen as

14 rivals but rather complementary strategies largely based on patient characteristics and

15 preference, and methodologically appropriate interpretation of the research evidence. The key

16 to the improvement in patients' outcome, as recommended, is the Heart Team discussion. ${ }^{11}$

17 The LMD controversy over the last few months highlights some key issues and responsibilities

18 of physicians, trialists, professional societies and, the cardiovascular community in general.

19 Trials should be designed to answer important clinical questions and have clinically relevant

20 and, where possible, standardized outcomes. The analytic approach, as well as a minimum

21 period of follow-up, should also be standardized. That is not to say that innovation is precluded. 
1 Indeed, the protocol-described strategy of the EXCEL investigators to use their new MI

2 definition, but in addition to publish the conventional Universal Definition of MI, was not

3 without merit. But both $\mathrm{Ml}$ outcomes should have been shared (or the protocol amended and

4 an explanation made in the paper).

5 The involvement of industry is important but needs to be clearly defined, and, ideally, trials

6 should be run and overseen by fully independent committees with appropriate transparency

7 and checks and balances in place. Like in other fields of science, data should be made available

8 to other investigators and be confirmed by independent groups not involved in the publication

9 of the initial trials.

10 The key to improving the outcome of patients with LMD (as well as other cardiovascular and

11 non-cardiovascular diseases) is the honest and transparent collaboration between all the

12 parties involved. After so much controversy, let's start again working together in the best

13 interest of our patients! 


\section{References}

1. Head SJ, Milojevic M, Daemen J, Ahn J-M, Boersma E, Christiansen EH, Domanski MJ, Farkouh ME, Flather M, Fuster V, Hlatky MA, Holm NR, Hueb WA, Kamalesh M, Kim Y-H, Mäkikallio T, Mohr FW, Papageorgiou G, Park S-J, Rodriguez AE, Sabik JF, Stables RH, Stone GW, Serruys PW, Kappetein AP. Mortality after coronary artery bypass grafting versus percutaneous coronary intervention with stenting for coronary artery disease: a pooled analysis of individual patient data. The Lancet 2018;391:939-948.

2. Freemantle N, Ruel M, Gaudino MFL, Pagano D. On the pooling and subgrouping of data from percutaneous coronary intervention versus coronary artery bypass grafting trials: a call to circumspection. Eur J Cardio-Thorac Surg;2018;53:915-918.

3. Stone GW, Kappetein AP, Sabik JF, Pocock SJ, Morice M-C, Puskas J, Kandzari DE, Karmpaliotis D, Brown WM, Lembo NJ, Banning A, Merkely B, Horkay F, Boonstra PW, Boven AJ van, Ungi I, Bogáts G, Mansour S, Noiseux N, Sabaté M, Pomar J, Hickey $M$, Gershlick A, Buszman PE, Bochenek A, Schampaert E, Pagé P, Modolo R, Gregson J, Simonton CA, et al. Five-Year Outcomes after PCl or CABG for Left Main Coronary Disease. $N$ Engl J Med 2019;381:1820-1830.

4. Serruys PW, Morice MC, Kappetein AP, Colombo A, Holmes DR, Mack MJ, Ståhle E, Feldman TE, van den Brand M, Bass EJ, Van Dyck N, Leadley K, Dawkins KD, Mohr FW; SYNTAX Investigators. Percutaneous coronary intervention versus coronary-artery bypass grafting for severe coronary artery disease. N Engl J Med 2009;360:961-72.

5. Farkouh ME, Domanski M, Sleeper LA, Siami FS, Dangas G, Mack M, Yang M, Cohen DJ, Rosenberg Y, Solomon SD, Desai AS, Gersh BJ, Magnuson EA, Lansky A, Boineau R, Weinberger J, Ramanathan K, Sousa JE, Rankin J, Bhargava B, Buse J, Hueb W, Smith CR, Muratov V, Bansilal S, King S 3rd, Bertrand M, Fuster V; FREEDOM Trial Investigators. Strategies for multivessel revascularization in patients with diabetes. $N$ Engl J Med 2012;367:2375-84.

6. European guidelines on heart disease under review - BBC Newsnight. https://youtu.be/_vGfJKMbpp8 (24 February, 2020)

7. EXCEL Investigators Respond to Data Suppression Claims as Debate Erupts Online. https://www.tctmd.com/news/excel-investigators-respond-data-suppression-claimsdebate-erupts-online (24 February, 2020)

8. Holm NR, Mäkikallio T, Lindsay MM, Spence MS, Erglis A, Menown IBA, Trovik T, Kellerth T, Kalinauskas G, Mogensen LJH, Nielsen PH, Niemelä M, Lassen JF, Oldroyd K, Berg G, Stradins P, Walsh SJ, Graham ANJ, Endresen PC, Fröbert O, Trivedi U, Anttila V, Hildick-Smith D, Thuesen L, Christiansen EH, NOBLE investigators. Percutaneous coronary angioplasty versus coronary artery bypass grafting in the treatment of unprotected left main stenosis: updated 5 -year outcomes from the randomised, non-inferiority NOBLE trial. The Lancet; 2020;395:191-199. 
9. Ahmad Y, Howard JP, Arnold AD, Cook CM, Prasad M, Ali ZA, Parikh MA, Kosmidou I, Francis D, Moses JW, Leon MB, Kirtane AJ, Stone GW, Karmpaliotis D. Mortality after drug-eluting stents versus coronary artery bypass grafting for left main coronary artery disease: A metaanalysis of randomized controlled trials Brief title: CABG versus PCI for LMCAD. Eur Heart J. In press.

10. Doenst T, Haverich A, Serruys P, Bonow RO, Kappetein P, Falk V, Velazquez E, Diegeler A, Sigusch H. PCl and CABG for Treating Stable Coronary Artery Disease: JACC Review Topic of the Week. J Am Coll Cardiol 2019;73:964-976.

11. Neumann FJ, Sousa-Uva M, Ahlsson A, Alfonso F, Banning AP, Benedetto U, Byrne RA, Collet JP, Falk V, Head SJ, Jüni P, Kastrati A, Koller A, Kristensen SD, Niebauer J, Richter DJ, Seferovic PM, Sibbing D, Stefanini GG, Windecker S, Yadav R, Zembala MO; ESC Scientific Document Group. 2018 ESC/EACTS Guidelines on myocardial revascularization. Eur Heart J. 2019;40:87-165. 
1 Figure 1. Treatment algorithm to be considered by the Heart Team deciding between coronary

2 artery bypass grafting (CABG) and percutaneous coronary intervention ( $\mathrm{PCI})$. LMD: left-main 3 disease; MVD: multi-vessel disease. 